\title{
Maintenance of Airway Pressure During Filter Exchange Due to Auto-Triggering
}

\author{
Joakim Engström MSc CCRN, Henrik Reinius MD, Camilla Fröjd PhD CCRN, \\ Hans Jonsson MSc CCRN, Göran Hedenstierna MD PhD, and Anders Larsson MD PhD
}

\begin{abstract}
BACKGROUND: Daily routine ventilator-filter exchange interrupts the integrity of the ventilator circuit. We hypothesized that this might reduce positive airway pressure in mechanically ventilated ICU patients, inducing alveolar collapse and causing impaired oxygenation and compliance of the respiratory system. METHODS: We studied 40 consecutive ICU subjects $\left(\mathrm{P}_{\mathrm{aO}}{ }_{2} / \mathrm{F}_{\mathrm{IO}_{2}}\right.$ ratio $\leq 300 \mathrm{~mm}$ $\mathrm{Hg}$ ), mechanically ventilated with pressure-regulated volume control or pressure support and PEEP $\geq 5 \mathrm{~cm} \mathrm{H}_{2} \mathrm{O}$. Before the filter exchange, (baseline) tidal volume, breathing frequency, end-inspiratory plateau pressure, and PEEP were recorded. Compliance of the respiratory system was calculated; $\mathrm{F}_{\mathrm{IO}}$, blood pressure, and pulse rate were registered; and $\mathrm{P}_{\mathrm{aO}}, \mathrm{P}_{\mathrm{aCO}}, \mathrm{pH}$, and base excess were measured. Measurements were repeated 15 and $60 \mathrm{~min}$ after the filter exchange. In addition, a bench test was performed with a precision test lung with similar compliance and resistance as in the clinical study. RESULTS: The exchange of the filter took $3.5 \pm 1.2 \mathrm{~s}$ (mean \pm SD). There was no significant change in $P_{a_{2}}(89 \pm 16 \mathrm{~mm} \mathrm{Hg}$ at baseline vs $86 \pm 16 \mathrm{~mm} \mathrm{Hg}$ at 15 min and $88 \pm 18 \mathrm{~mm} \mathrm{Hg}$ at $60 \mathrm{~min}, P=.24)$ or in compliance of the respiratory system $(41 \pm 11$ $\mathrm{mL} / \mathrm{cm} \mathrm{H}_{2} \mathrm{O}$ at baseline vs $40 \pm 12 \mathrm{~mL} / \mathrm{cm} \mathrm{H}_{2} \mathrm{O}$ at $15 \mathrm{~min}$ and $40 \pm 12 \mathrm{~mL} / \mathrm{cm} \mathrm{H}_{2} \mathrm{O}$ at $60 \mathrm{~min}, P=$ .32). The bench study showed that auto-triggering by the ventilator when disconnecting from the expiratory circuit kept the tracheal pressure above PEEP for at least $3 \mathrm{~s}$ with pressure controlled ventilation. CONCLUSIONS: This study showed that a short disconnection of the expiratory ventilator circuit from the ventilator during filter exchange was not associated with any significant deterioration in lung function 15 and 60 min later. This result may be explained by auto-triggering of the ventilator with high inspiratory flows during the filter exchange, maintaining airway pressure. (ISRCTN.org registration ISRCTN76631800.) Key words: acute lung injury; positive-pressure respiration; positive end-expiratory pressure; air filters; intensive care units. [Respir Care 2014;59(8):1210-1217. (C) 2014 Daedalus Enterprises]
\end{abstract}

\section{Introduction}

PEEP is used to prevent alveolar de-recruitment and maintain oxygenation in mechanically ventilated patients

\footnotetext{
Mr Engström, Dr Reinius, Dr Fröjd, Mr Jonsson, and Dr Larsson are affiliated with Anesthesiology and Intensive Care, Department of Surgical Sciences, Uppsala University; Dr Hedenstierna is affiliated with the Department of Medical Sciences, Uppsala University, Uppsala, Sweden.

This research was supported by the Swedish Heart-Lung Foundation, by Swedish Research Council Uppsala county grant 5315 , and by an institutional grant from the Department of Surgical Sciences, Anesthesiology and Intensive Care, Uppsala University. The authors have disclosed no conflicts of interest.
}

with lungs prone to atelectasis, eg, in ARDS. ${ }^{1,2}$ It has been found in experimental ARDS models that lung collapse occurs within seconds after discontinuation of positive airway pressure. ${ }^{3}$ In fact, Neumann et $\mathrm{a}^{3}$ showed that the time constant for development of a major collapse was $0.6 \mathrm{~s}$. It is well known that oxygenation deteriorates when the endotracheal tube is disconnected from the ventilator circuit in mechanically ventilated ICU patients, particu-

\footnotetext{
Correspondence: Joakim Engström MSc CCRN, Department of Surgical Sciences, Uppsala University, SE-751 85 Uppsala, Sweden. E-mail: joakim.engstrom@surgsci.uu.se.
}

DOI: $10.4187 /$ respcare.02892 
larly in connection with endotracheal suctioning. ${ }^{4-6}$ Moreover, the sole removal of positive airway pressure causes a marked decrease in lung volume. ${ }^{5,7}$ In our ICU, we routinely exchange ventilator filters every $24 \mathrm{~h}$ for hygienic reasons, in accordance with the recommendations by the manufacturer. ${ }^{8}$ These filters are placed between the expiratory limb of the ventilatory tubing and the ventilator. Because this procedure breaks the integrity of the ventilatory circuit, we hypothesized that this could compromise lung function, something that is not recognized or discussed either in the clinic or in studies of different ventilatory strategies. Therefore, the aim of this study was to assess whether the daily routine exchange of ventilator filters would lead to deterioration of oxygenation or compliance of the respiratory system in mechanically ventilated ICU patients. To further explore the mechanisms, we assessed the airway pressure change proximal to the tip of the endotracheal tube in a bench test after a simulated filter exchange.

\section{Methods}

The study was divided into 2 parts: (1) a clinical study in 40 mechanically ventilated subjects (Fig. 1) and (2) a bench test using different ventilatory modes to estimate the pressure change distal to the endotracheal tube at a simulated ventilator filter exchange (Fig. 2).

\section{The Clinical Study}

The study was performed in Anesthesiology and Intensive Care, Department of Surgical Sciences, Uppsala University, Uppsala, Sweden. The study was approved by the university ethics committee (ISRCTN.org registration ISRCTN76631800). Informed consent was obtained from the subjects' next of kin before inclusion.

Mechanically ventilated subjects were included consecutively if: $\mathrm{P}_{\mathrm{aO}_{2}} / \mathrm{F}_{\mathrm{IO}_{2}}$ ratio was $\leq 300 \mathrm{~mm} \mathrm{Hg}$, PEEP was $\geq 5 \mathrm{~cm} \mathrm{H}_{2} \mathrm{O}$, patient had an arterial cannula, patient was $\geq 18 \mathrm{y}$, and patient was not pregnant.

\section{Protocol}

The subjects were mechanically ventilated with pressure-regulated volume control (PRVC), pressure controlled ventilation, or pressure support ventilation using a Servo-i ventilator (Maquet, Wayne, New Jersey). Flow triggering was used and set at $1 \mathrm{~L} / \mathrm{min}$ in all subjects. The inspiratory rise time was set at $5 \%$. The ventilator tubing circuit set (A4VXXXXX, Vital Signs, Totowa, New Jersey) had an inner diameter of $22 \mathrm{~mm}$ and was $275 \mathrm{~cm}$ in length (137.5 cm inspiratory and $137.5 \mathrm{~cm}$ expiratory limb). The size of the endotracheal tube (ETT) (Portex Blue Line Sacett, Smiths Medical, Hythe, Kent, United Kingdom) or

\section{QUICK LOOK}

\section{Current knowledge}

Breathing circuit filters in the expiratory limb of the ventilator circuit protect ventilator components from moisture and contamination. Daily routine changes of breathing circuit filters are recommended to prevent increased expiratory resistance and untoward events. Changing the filter requires breaking the circuit, loss of airway pressure, and the potential for lung de-recruitment.

\section{What this paper contributes to our knowledge}

In a group of mechanically ventilated patients with hypoxemia, a short disconnection of the expiratory ventilator circuit during filter exchange was not associated with any significant deterioration in lung function. This may be explained by auto-triggering of the ventilator with high inspiratory flow, maintaining airway pressure.

tracheostomy tube (Shiley Evac tracheostomy tube cuffed system, Covidien, Mansfield, Ohio) was recorded, as well as whether a heat-moisture exchanger (HME, Pharma Systems, Knivsta, Sweden) or an active humidifier (RT430, Fisher \& Paykel Healthcare, Auckland, New Zealand) was used.

Before the exchange of the high-efficiency particulate air filter (Servo Duo Gard, Maquet), placed between the expiratory limb of the ventilatory circuit and the ventilator, tidal volume, breathing frequency, end-inspiratory plateau pressure (EIP), and PEEP were recorded (baseline). In the subjects with controlled ventilation without any subjecttriggered breaths $(n=32)$, compliance was calculated as tidal volume/(EIP - PEEP). Both EIP and PEEP were measured after a prolonged pause of $10 \mathrm{~s}$. $\mathrm{F}_{\mathrm{IO}_{2}}$, arterial blood pressure, and pulse rate were recorded, and arterial blood was sampled for determination of $\mathrm{P}_{\mathrm{aO}_{2}}, \mathrm{P}_{\mathrm{aCO}_{2}}, \mathrm{pH}$, and base excess (ABL800 Flex, Radiometer, Brondby, Denmark).

The subject remained connected to the ventilator during the whole filter exchange procedure. The expiratory tubing was disconnected from the old filter, which was then removed from the ventilator inlet and exchanged, and the expiratory tubing was reconnected to the new filter. Measurements were repeated 15 and $60 \mathrm{~min}$ after the filter exchange. In addition, the duration of the exchange procedure was recorded. Finally, in 4 subjects, airway pressure $\left(\mathrm{P}_{\mathrm{aw}}\right)$ was measured in the $\mathrm{Y}$-piece connected to the ETT and $1 \mathrm{~cm}$ below the ETT tip via a $15 \mathrm{~cm}, 16$ gauge catheter (Arrow, Limerick, Pennsylvania). Endotracheal 


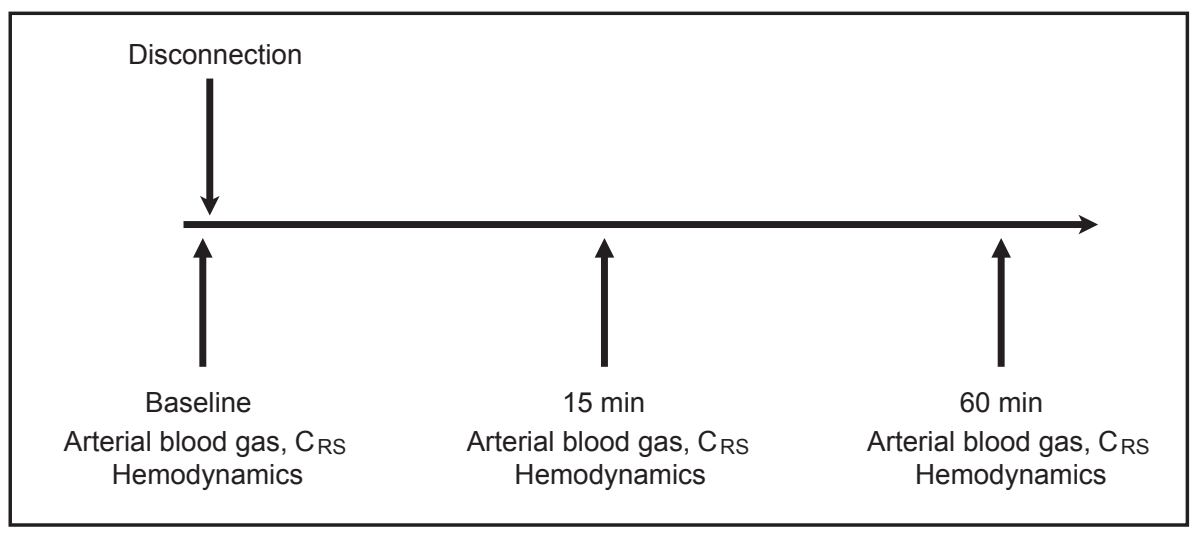

Fig. 1. Outline of the study. The arrows above the horizontal line indicate interventions, whereas the arrows below the line indicate measurements. $\mathrm{C}_{\mathrm{RS}}=$ compliance of the respiratory system.

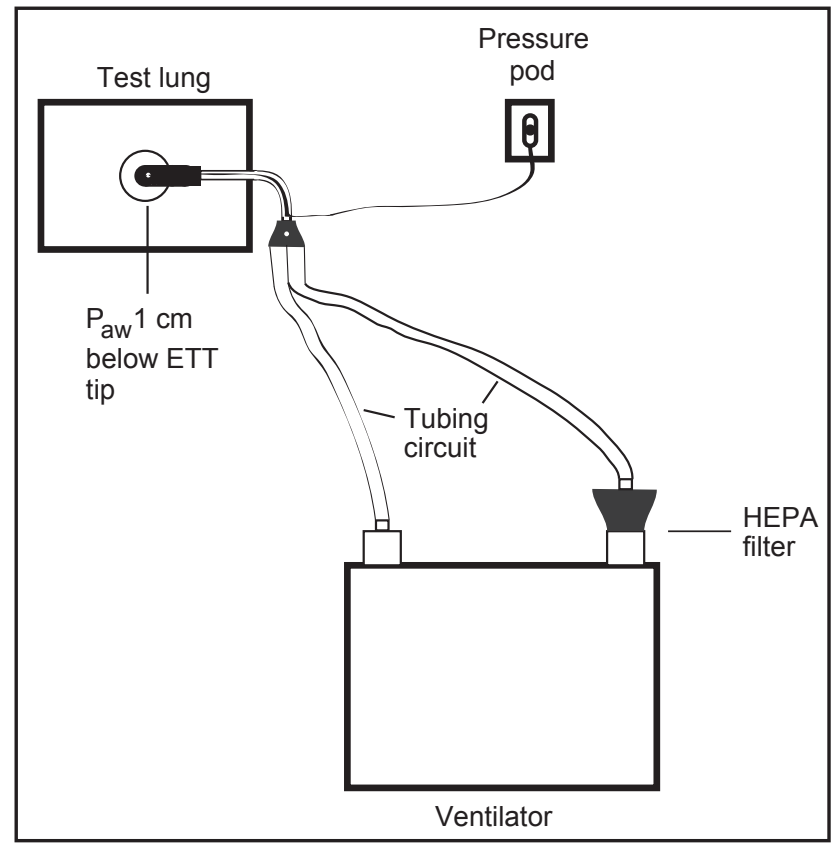

Fig. 2. Experimental setup of the bench test. The high-efficiency particulate air filter was placed in the expiratory limb of ventilator. $\mathrm{P}_{\mathrm{aw}}=$ airway pressure. ETT = endotracheal tube.

disconnection and suctioning were not performed in any subject for at least $4 \mathrm{~h}$ before study inclusion. No changes were made in subject position or ventilator settings during the study protocol.

\section{Bench Test}

The "tracheal" airway pressure decrease was measured in a lung model (Accu Lung precision test lung, Fluke Biomedical, Everett, Washington).

The test lung was set at compliance values 10 or $20 \mathrm{~mL} / \mathrm{cm} \mathrm{H}_{2} \mathrm{O}$, resistance $5 \mathrm{~cm} \mathrm{H}_{2} \mathrm{O} / \mathrm{L} / \mathrm{s}$ (the resistance
Table 1. Subject Characteristics

\begin{tabular}{|c|c|}
\hline Subject Characteristics $(N=40)$ & Values \\
\hline Age (y) & $64 \pm 15$ \\
\hline Female sex $(n, \%)$ & $12(30)$ \\
\hline SAPS III & $67 \pm 14$ \\
\hline Duration of mechanical ventilation (d) & $8.6 \pm 9.9$ \\
\hline ICU stay (d) & $10 \pm 11$ \\
\hline Hospital stay (d) & $31 \pm 38$ \\
\hline ICU mortality $(n, \%)$ & $5(13)$ \\
\hline 30-d mortality $(n, \%)$ & $9(23)$ \\
\hline \multicolumn{2}{|l|}{ ARDS } \\
\hline Mild $(n, \%)$ & $13(32.5)$ \\
\hline Moderate $(n, \%)$ & $25(62.5)$ \\
\hline Severe $(n, \%)$ & $2(5)$ \\
\hline \multicolumn{2}{|l|}{ Mechanical ventilation settings } \\
\hline Tidal volume $(\mathrm{mL} / \mathrm{kg})$ & $7.2 \pm 1.6$ \\
\hline Breathing frequency (breaths/min) & $12 \pm 5$ \\
\hline $\mathrm{F}_{\mathrm{IO}_{2}}$ & $0.5 \pm 0.1$ \\
\hline $\operatorname{EIP}\left(\mathrm{cm} \mathrm{H}_{2} \mathrm{O}\right)$ & $24 \pm 5$ \\
\hline PEEP $\left(\mathrm{cm} \mathrm{H}_{2} \mathrm{O}\right)$ & $12 \pm 4$ \\
\hline \multicolumn{2}{|l|}{ Gas exchange } \\
\hline Arterial $\mathrm{pH}$ & $7.39 \pm 0.07$ \\
\hline $\mathrm{P}_{\mathrm{aCO}_{2}}(\mathrm{~mm} \mathrm{Hg})$ & $45 \pm 14$ \\
\hline $\mathrm{P}_{\mathrm{aO}_{2}}(\mathrm{~mm} \mathrm{Hg})$ & $89 \pm 16$ \\
\hline $\mathrm{C}_{\mathrm{RS}}\left(\mathrm{mL} / \mathrm{cm} \mathrm{H}_{2} \mathrm{O}\right)$ & $41 \pm 11$ \\
\hline $\mathrm{BE}(\mathrm{mmol} / \mathrm{L})$ & $1.0 \pm 4.9$ \\
\hline \multicolumn{2}{|l|}{ Circulatory parameters } \\
\hline Mean arterial pressure $(\mathrm{mm} \mathrm{Hg})$ & $77 \pm 14$ \\
\hline Pulse rate (beats/min) & $88 \pm 23$ \\
\hline \multicolumn{2}{|l|}{$\begin{array}{l}\text { Values are mean } \pm \text { SD unless otherwise specified. } \\
\text { SAPS III }=\text { simplified acute physiology score III } \\
\text { EIP }=\text { end-inspiratory plateau pressure } \\
C_{\mathrm{RS}}=\text { compliance of the respiratory system } \\
\mathrm{BE}=\text { base excess }\end{array}$} \\
\hline
\end{tabular}

setting was chosen to avoid inadvertent auto-PEEP), and was connected through an inner diameter 6 or $8 \mathrm{~mm}$ ETT (Portex Blue Line Sacett, Smiths Medical International) 
Table 2. Individual ARDS, $\mathrm{P}_{\mathrm{aO}_{2}} / \mathrm{F}_{\mathrm{IO}_{2}}, \mathrm{PEEP}, \mathrm{P}_{\mathrm{aO}_{2}}$, and $\mathrm{C}_{\mathrm{RS}}$ Before the High-Efficiency Particulate Air Filter Change and 15 and 60 Min Afterward

\begin{tabular}{|c|c|c|c|c|c|c|c|c|c|}
\hline \multirow{2}{*}{ Subject No. } & \multirow{2}{*}{ ARDS* } & \multirow{2}{*}{$\begin{array}{l}\mathrm{P}_{\mathrm{aO}_{2}} / \mathrm{F}_{\mathrm{IO}_{2}} \\
(\mathrm{~mm} \mathrm{Hg})\end{array}$} & \multirow{2}{*}{$\begin{array}{c}\text { PEEP } \\
\left(\mathrm{cm} \mathrm{H} \mathrm{H}_{2} \mathrm{O}\right)\end{array}$} & \multicolumn{3}{|c|}{$\mathrm{P}_{\mathrm{aO}_{2}}(\mathrm{~mm} \mathrm{Hg})$} & \multicolumn{3}{|c|}{$\mathrm{C}_{\mathrm{RS}}\left(\mathrm{mL} / \mathrm{cm} \mathrm{H} \mathrm{H}_{2} \mathrm{O}\right)$} \\
\hline & & & & Baseline & $15 \mathrm{~min}$ & $60 \mathrm{~min}$ & Baseline & $15 \mathrm{~min}$ & $60 \mathrm{~min}$ \\
\hline 1 & 2 & 156 & 17 & 94 & 95 & 80 & 53 & 53 & 60 \\
\hline 2 & 3 & 231 & 15 & 116 & 116 & 95 & 40 & 37 & 37 \\
\hline 3 & 3 & 200 & 12 & 120 & 83 & 81 & $\mathrm{NA} \dagger$ & NA & NA \\
\hline 4 & 3 & 222 & 11 & 122 & 106 & 96 & 37 & 34 & 37 \\
\hline 5 & 1 & 82 & 13 & 66 & 56 & 57 & 48 & 44 & 44 \\
\hline 6 & 2 & 194 & 16 & 107 & 121 & 145 & 40 & 30 & 35 \\
\hline 7 & 2 & 131 & 17 & 72 & 62 & 61 & 38 & 30 & 28 \\
\hline 8 & 2 & 122 & 17 & 73 & 71 & 70 & 22 & 27 & 26 \\
\hline 9 & 2 & 108 & 13 & 76 & 74 & 75 & 43 & 42 & 43 \\
\hline 10 & 2 & 166 & 17 & 92 & 81 & 85 & 43 & 45 & 45 \\
\hline 11 & 2 & 142 & 17 & 71 & 67 & 69 & 25 & 25 & 22 \\
\hline 12 & 1 & 89 & 12 & 67 & 64 & 73 & 53 & 50 & 55 \\
\hline 13 & 2 & 113 & 16 & 79 & 79 & 86 & 33 & 29 & 30 \\
\hline 14 & 2 & 139 & 12 & 83 & 80 & 85 & 35 & 35 & 42 \\
\hline 15 & 2 & 155 & 16 & 93 & 92 & 87 & 40 & 30 & 35 \\
\hline 16 & 3 & 231 & 19 & 116 & 116 & 113 & 47 & 43 & 43 \\
\hline 17 & 2 & 126 & 14 & 95 & 95 & 97 & 59 & 58 & 59 \\
\hline 18 & 2 & 164 & 11 & 90 & 98 & 114 & 60 & 60 & 60 \\
\hline 19 & 2 & 156 & 10 & 78 & 89 & 98 & 26 & 27 & 26 \\
\hline 20 & 2 & 158 & 5 & 79 & 71 & 69 & 15 & 16 & 17 \\
\hline 21 & 3 & 207 & 5 & 93 & 83 & 87 & 50 & 50 & 49 \\
\hline 22 & 2 & 197 & 8 & 98 & 93 & 92 & NA & NA & NA \\
\hline 23 & 3 & 208 & 10 & 73 & 70 & 68 & NA & NA & NA \\
\hline 24 & 3 & 218 & 10 & 98 & 102 & 107 & NA & NA & NA \\
\hline 25 & 2 & 186 & 5 & 93 & 85 & 86 & NA & NA & NA \\
\hline 26 & 2 & 189 & 12 & 76 & 72 & 77 & NA & NA & NA \\
\hline 27 & 2 & 143 & 13 & 93 & 85 & 86 & 37 & 34 & 35 \\
\hline 28 & 2 & 153 & 12 & 69 & 67 & 65 & NA & NA & NA \\
\hline 29 & 2 & 134 & 8 & 80 & 83 & 78 & 41 & 41 & 41 \\
\hline 30 & 3 & 257 & 18 & 116 & 116 & 107 & 26 & 26 & 28 \\
\hline 31 & 2 & 191 & 15 & 105 & 108 & 123 & 30 & 20 & 30 \\
\hline 32 & 3 & 230 & 12 & 69 & 78 & 80 & NA & NA & NA \\
\hline 33 & 3 & 237 & 8 & 107 & 103 & 105 & 52 & 52 & NA \\
\hline 34 & 2 & 185 & 11 & 74 & 76 & 80 & 44 & 64 & 54 \\
\hline 35 & 2 & 162 & 15 & 89 & 95 & 104 & 40 & 38 & 40 \\
\hline 36 & 2 & 133 & 9 & 86 & 87 & 77 & 46 & 45 & 38 \\
\hline 37 & 3 & 229 & 6 & 92 & 83 & 83 & NA & NA & NA \\
\hline 38 & 3 & 219 & 9 & 77 & 72 & 69 & 52 & 53 & 54 \\
\hline 39 & 3 & 289 & 5 & 101 & 85 & 96 & 50 & 49 & 49 \\
\hline 40 & 2 & 198 & 7 & 89 & 95 & 98 & 45 & 46 & 47 \\
\hline Mean \pm SD & & $176 \pm 47$ & $12 \pm 4$ & $89 \pm 16$ & $86 \pm 16$ & $88 \pm 18$ & $41 \pm 11$ & $40 \pm 12$ & $40 \pm 12$ \\
\hline \multicolumn{10}{|c|}{$\begin{array}{l}* \text { ARDS severity is divided in three classes: (1) severe, (2) moderate, and (3) mild. } \\
\dagger \mathrm{NA}=\text { missing value due to spontaneous breathing } \\
\mathrm{C}_{\mathrm{RS}}=\text { compliance of the respiratory system }\end{array}$} \\
\hline
\end{tabular}

and a 275-cm, inner diameter $22 \mathrm{~mm}$ tubing circuit (A4VXXXXX, Vital Signs, the same as used in the clinic) to a Servo-i ventilator (Maquet) set at either pressure controlled ventilation (EIP $25 \mathrm{~cm} \mathrm{H}_{2} \mathrm{O}, 10 \mathrm{~cm} \mathrm{H}_{2} \mathrm{O}$ PEEP, or volume controlled ventilation with the same EIP and PEEP as during pressure controlled ventilation. The ratio of inspiratory time to expiratory time (I-E ratio) was 1:2 and the rate 15 or $25 / \mathrm{min}$. The inspiratory rise time was set at $5 \%$ (similar to subject values), $\mathrm{P}_{\text {aw }}$ was measured $1 \mathrm{~cm}$ below the ETT tip in the test lung via a $15 \mathrm{~cm}, 16$ gauge catheter (Arrow). At each of the above combinations, the expiratory circuit was disconnected from the ventilator during 2, 3, 4, 5, 6, and $10 \mathrm{~s}$ to simulate filter exchange. The filter was disconnected from the tubing. Flow trigger 
set at $1 \mathrm{~L} / \mathrm{min}$ and pressure trigger set at $-20 \mathrm{~cm} \mathrm{H}_{2} \mathrm{O}$ were used at every step. In addition, the suctioning support function was activated at the end of each sequence. During all the procedures, inspiratory flow (obtained from the ventilator) and tracheal pressure were registered.

\section{Statistics}

The primary outcome variables were changes in $\mathrm{P}_{\mathrm{aO}_{2}}$. A power analysis indicated that for a clinically important decrease in $\mathrm{P}_{\mathrm{aO}_{2}}(10 \pm 15 \mathrm{~mm} \mathrm{Hg}$ [mean $\pm \mathrm{SD}$ ]) with a $P<.05$ and a power of $0.95,32$ subjects would be needed. We therefore enrolled 40 subjects in this study. The data were analyzed by one-way analysis of variance.

The data from the bench test were analyzed with the $t$ test.

For the statistical analyses, the Prism 6.0 statistical program (GraphPad Software, La Jolla, California) was used. $P<.05$ was considered a priori as statistically significant.

\section{Results}

\section{Clinical Study}

Twelve women and 28 men ( 2 with severe, 25 with moderate, and 13 with mild ARDS $^{9}$ ) were enrolled (Table 1); 8 were ventilated with pressure support ventilation, 12 with pressure controlled ventilation, and 20 with PRVC; 39 of the subjects were orally intubated, and one had a tracheal cannula. PEEP was $12.0 \pm 4.0 \mathrm{~cm} \mathrm{H}_{2} \mathrm{O}, \mathrm{F}_{\mathrm{IO}_{2}}$ was $0.5 \pm 0.1$, and the $\mathrm{P}_{\mathrm{aO}_{2}} / \mathrm{F}_{\mathrm{IO}_{2}}$ ratio was $176 \pm 47 \mathrm{~mm} \mathrm{Hg}$. The mean time on the ventilator was $8.6 \pm 9.9 \mathrm{~d}$. The tube sizes used in the studied subjects were inner diameter $7 \mathrm{~mm}$ for women $(n=12)$ and inner diameter $8 \mathrm{~mm}$ for men $(n=28)$. The gas was humidified with a heat-moisture exchanger in 20 subjects and with an active humidifier for the remaining subjects $(n=20)$.

The mean duration of the filter exchange was $3.5 \pm$ $1.2 \mathrm{~s}$. There were no significant changes in $\mathrm{P}_{\mathrm{aO}_{2}}(89 \pm 16$ $\mathrm{mm} \mathrm{Hg}$ at baseline vs $86 \pm 16 \mathrm{~mm} \mathrm{Hg}$ at $15 \mathrm{~min}$ and 88 $\pm 18 \mathrm{~mm} \mathrm{Hg}$ at $60 \mathrm{~min}, P=.24$; Table 2, Fig. 3) or in compliance of the respiratory system $(41 \pm 11 \mathrm{~mL} / \mathrm{cm}$ $\mathrm{H}_{2} \mathrm{O}$ at baseline vs $40 \pm 12 \mathrm{~mL} / \mathrm{cm} \mathrm{H}_{2} \mathrm{O}$ at $15 \mathrm{~min}$ and 40 $\pm 12 \mathrm{~mL} / \mathrm{cm} \mathrm{H}_{2} \mathrm{O}$ at $60 \mathrm{~min}, P=.32$; Table 2, Fig. 3). Arterial pH $(7.39 \pm 0.07$ at baseline vs $7.39 \pm 0.08$ at $15 \mathrm{~min}$ and $7.39 \pm 0.08$ at $60 \mathrm{~min})$ and $\mathrm{P}_{\mathrm{aCO}_{2}}(43 \pm 10 \mathrm{~mm}$ $\mathrm{Hg}$ at baseline vs $43 \pm 10 \mathrm{~mm} \mathrm{Hg}$ at $15 \mathrm{~min}$ and $44 \pm$ $11 \mathrm{~mm} \mathrm{Hg}$ at $60 \mathrm{~min}$ ) as well as hemodynamics (pulse rate $88 \pm 23$ beats $/ \mathrm{min}$ at baseline vs $88 \pm 21$ beats $/ \mathrm{min}$ at $15 \mathrm{~min}$ and $87 \pm 20$ beats/min at $60 \mathrm{~min}$ [MAP $77 \pm 14$ $\mathrm{mm} \mathrm{Hg}$ at baseline vs $75 \pm 15 \mathrm{~m} \mathrm{Hg}$ at $15 \mathrm{~min}$ and $75 \pm$ $10 \mathrm{~mm} \mathrm{Hg}$ at $60 \mathrm{~min}]$ ) did not change during the study period.

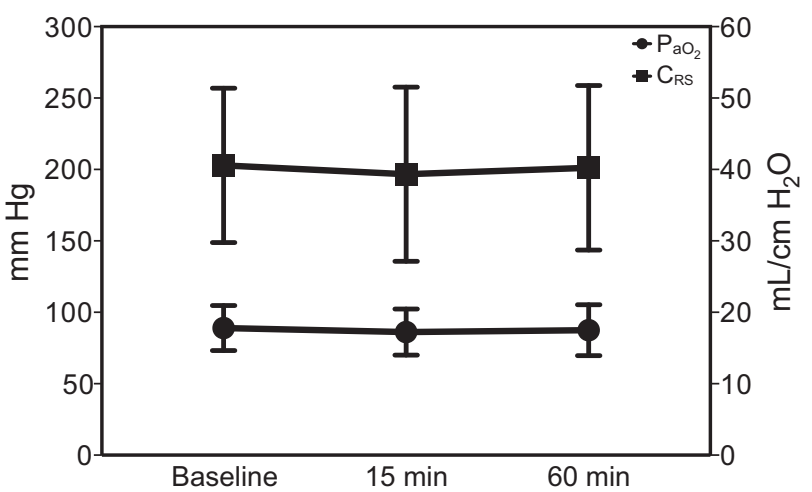

Fig. 3. Mean $\mathrm{P}_{\mathrm{aO}_{2}}(\mathrm{~mm} \mathrm{Hg})$ and compliance of the respiratory system $\left(\mathrm{C}_{\mathrm{RS}} ; \mathrm{mL} / \mathrm{cm} \mathrm{H}_{2} \mathrm{O}\right)$ with SD before the high-efficiency particulate air filter change and $15 \mathrm{~min}$ and $60 \mathrm{~min}$ after.

Table 3. Airway Pressure $\left(\mathrm{P}_{\mathrm{aw}}\right)$ During the High-Efficiency Particulate Air Filter Change

\begin{tabular}{lcccc}
\hline \hline $\begin{array}{c}\text { Subject } \\
\text { No. }\end{array}$ & $\begin{array}{c}\text { Disconnection } \\
\text { Time }(\mathrm{s})\end{array}$ & $\begin{array}{c}\text { ETT Size } \\
(\mathrm{mm}, \text { inner diameter })\end{array}$ & $\begin{array}{c}\text { PEEP } \\
\left(\mathrm{cm} \mathrm{H}_{2} \mathrm{O}\right)\end{array}$ & $\begin{array}{c}\mathrm{P}_{\mathrm{aw}} \\
\left(\mathrm{cm} \mathrm{H}_{2} \mathrm{O}\right)\end{array}$ \\
\hline 17 & 3.0 & 7 & 14 & 14 \\
35 & 3.0 & 8 & 15 & 14 \\
38 & 3.0 & 8 & 9 & 8 \\
39 & 3.5 & 8 & 5 & 5 \\
& & & & \\
$\begin{array}{l}\mathrm{P} \\
\mathrm{P}\end{array}$ & & & \\
$\mathrm{ETT}=$ airway pressure & & & \\
\end{tabular}

In the 4 subjects (Nos. 17, 35, 38, and 39, all ventilated with PRVC) where the pressure below the ETT was measured, the airway pressure was maintained above PEEP in all subjects during the $3-3.5$-s disconnection period (Table 3).

\section{Bench Test}

After disconnection of the ventilator circuit, the ventilator delivered 4 auto-triggered inspirations with a total duration of 3-10 s, depending on the I-E ratio and the set breathing frequency. The inspiratory flow pattern differed between the 2 ventilation modes. In the pressure controlled ventilation mode, the inspiratory flow reached a maximum rate of $3,300 \mathrm{~mL} / \mathrm{s}$ in $0.3 \mathrm{~s}$ in all auto-triggered inspirations. In the volume controlled ventilation mode, flow of the first triggered inspiration was the same as with the pressure controlled ventilation $(3,300 \mathrm{~mL} / \mathrm{s})$ mode, but flow took $1.2 \mathrm{~s}$ to reach its maximum rate. Flow in the volume controlled ventilation mode decreased in inspiration numbers 2, 3, and 4 to $2,500 \mathrm{~mL} / \mathrm{s}$. With pressure controlledventilation, $\mathrm{P}_{\mathrm{aw}}$ was maintained above the set PEEP of $10 \mathrm{~cm} \mathrm{H}_{2} \mathrm{O}$ in all cases. The lowest $\mathrm{P}_{\mathrm{aw}}(12 \pm 1.2 \mathrm{~cm}$ $\mathrm{H}_{2} \mathrm{O}$ ) was independent of other settings and tube size. 

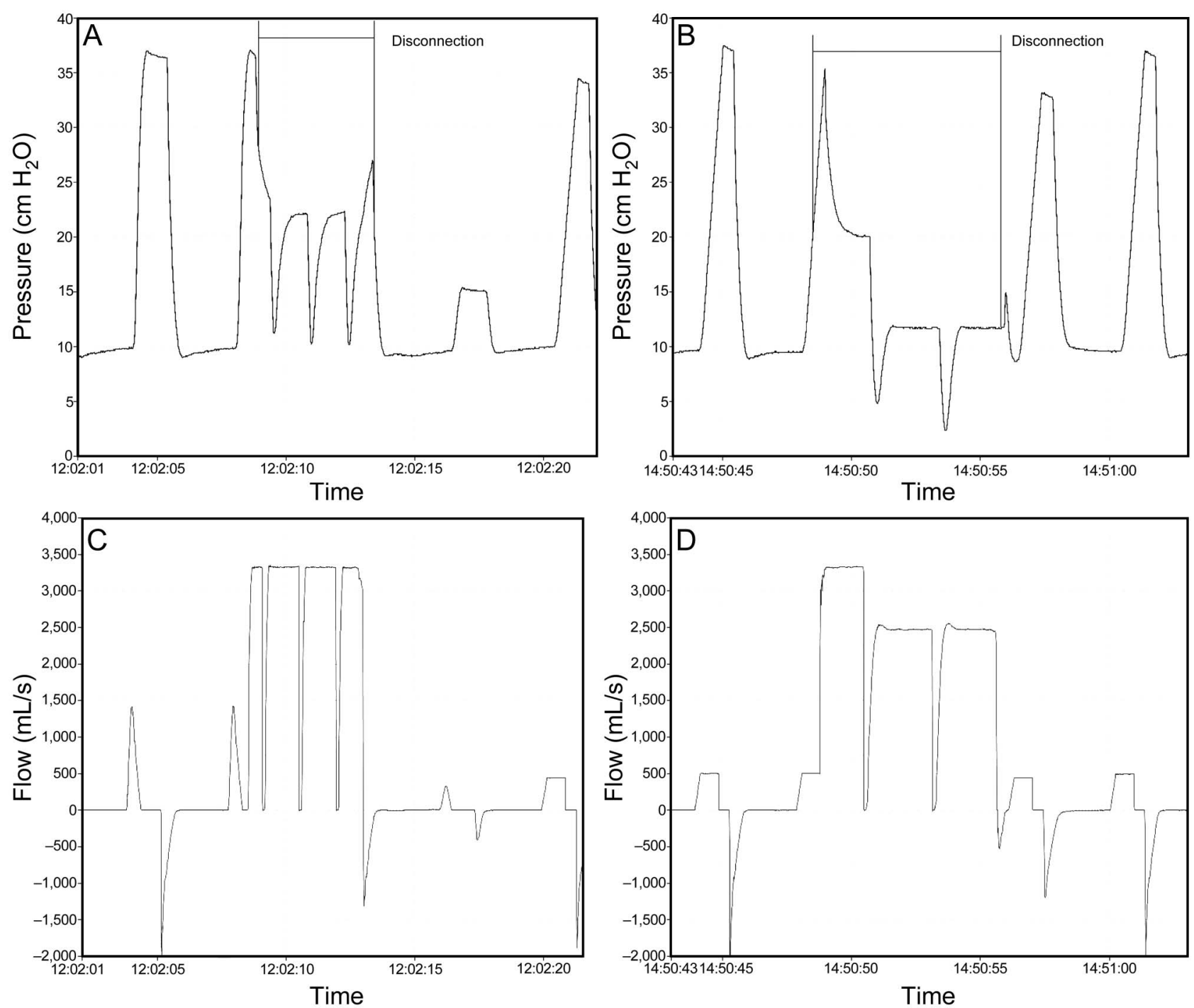

Fig. 4. Airway pressure $1 \mathrm{~cm}$ below an inner diameter $8 \mathrm{~mm}$ endotracheal tube tip during experimental high-efficiency particulate air filter change in the bench model. A and C: the ventilator was set at pressure controlled ventilation (end-inspiratory plateau pressure $25 \mathrm{~cm} \mathrm{H}_{2} \mathrm{O}$ ), breathing frequency of 15 breaths/min, ratio of inspiratory time to expiratory time 1:2, flow triggering $1 \mathrm{~L} / \mathrm{min}$. B and D: for volume controlled ventilation, the settings were the same as during pressure controlled ventilation. The test lung was set to compliance $10 \mathrm{~mL} / \mathrm{cm} \mathrm{H}_{2} \mathrm{O}$.

However, with volume controlled ventilation, $\mathrm{P}_{\mathrm{aw}}$ decreased to a minimum of $4.3 \pm 1.2 \mathrm{~cm} \mathrm{H}_{2} \mathrm{O}(P<.001$ compared with pressure controlled ventilation) (Fig. 4). In both pressure controlled ventilation and volume controlled ventilation, $\mathrm{P}_{\mathrm{aw}}$ decreased to $0 \mathrm{~cm} \mathrm{H}_{2} \mathrm{O} 0.7 \pm 0.2 \mathrm{~s}$ after the auto-triggered inspirations discontinued. With the suction support function activated, $\mathrm{P}_{\mathrm{aw}}$ decreased to $0 \mathrm{~cm}_{2} \mathrm{O}$ within $1.7 \pm 0.4 \mathrm{~s}$ after disconnection (Fig. 5), and the same pattern occurred with the $-20 \mathrm{~cm} \mathrm{H}_{2} \mathrm{O}$ trigger setting.

\section{Discussion}

This study shows that exchange of ventilator filters placed between the expiratory limb of the ventilatory circuit and the ventilator did not deteriorate lung function, as assessed by arterial oxygenation and respiratory system compliance in subjects mechanically ventilated with a Servo-i ventilator with PRVC or pressure support ventilation with low flow triggering settings. Tracheal pressure monitoring in 4 subjects indicated that the pressure did not decrease during the short disconnection procedure. The bench test demonstrated that disconnection during pressure controlled ventilation induced auto-triggering of the ventilator, thus maintaining the airway pressure. However, in the bench test, with volume controlled ventilation using a 5\% rise time similar to that with pressure controlled ventilation, there was a delay in achieving maximal flow at auto-triggering, causing an initial drop in airway pressure. When turning off the trigger, the airway pressure 

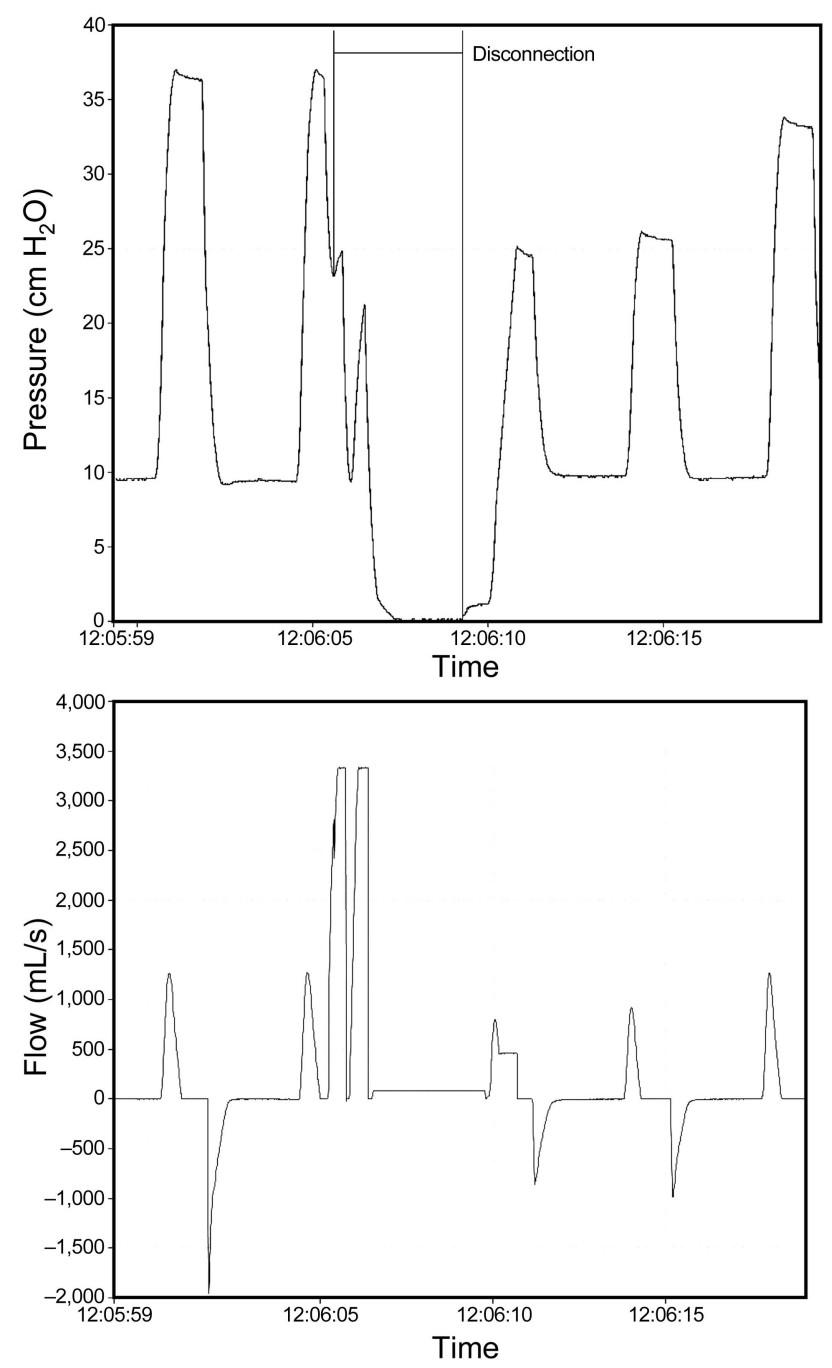

Fig. 5. Airway pressure $1 \mathrm{~cm}$ below inner diameter $8 \mathrm{~mm}$ endotracheal tube tip during experimental high-efficiency particulate air filter change in the bench model with suction support activated. The ventilator was set for pressure controlled ventilation (endinspiratory plateau pressure $25 \mathrm{~cm} \mathrm{H}_{2} \mathrm{O}$ ), breathing frequency of 15 breaths $/ \mathrm{min}$, ratio of inspiratory time to expiratory time $1: 2$, flow triggering $1 \mathrm{~L} / \mathrm{min}$. The test lung was set to compliance $10 \mathrm{~mL} / \mathrm{cm}$ $\mathrm{H}_{2} \mathrm{O}$.

immediately decreased to zero in both volume controlled ventilation and pressure controlled ventilation mode.

Two factors are important to explain the clinical results in the subjects. First, the trigger was set at low triggering effort, causing the ventilator to easily sense a loss of airway pressure, which the ventilator software interpreted as a trigger effort, inducing a new inspiration with a duration as set by the I-E ratio and ventilatory rate. Without any trigger, the disconnection of the ventilator circuit would not induce any new breaths. Second, in both PRVC and pressure support ventilation, the ventilator delivers a pressure-regulated breath, and therefore the upper flow rate is only limited by the capacity of the ventilator to deliver gas flow and the resistance in the ventilator tubings. Thus, as shown in the bench test and in the 4 subjects in whom we measured tracheal pressure, the high flow combined with the resistance in the expiratory tubing generated an airway pressure higher or equal to the set PEEP. However, one cannot exclude the possibility that, in our group of subjects with mainly mild to moderate ARDS, oxygenation recovered fast, explaining our results. Theoretically, with volume controlled ventilation, which delivers a specific volume with a limited square wave flow pattern, the flow should not be high enough to maintain an adequate airway pressure level. However, unexpectedly, in the bench test the flow with volume controlled ventilation increased to approximately $3 \mathrm{~L} / \mathrm{s}$ after a short delay, corresponding to the set rise time and a flow trigger delay of $100 \mathrm{~ms}$, inducing only a short drop in airway pressure (Fig. 4). This is because the Servo-i has temporary pressure support in the volume controlled ventilation mode that is switched on when the inspiratory pressure drops below $3 \mathrm{~cm} \mathrm{H}_{2} \mathrm{O}$ the expected pressure value during inspiration, indicating that the flow demand of the patient is higher than the ventilator is set to deliver. However, this temporary pressure support feature is model-dependent and can be deactivated in newer models for the United States market of the Servo-i (Åke Larsson, Maquet Critical Care, Solna, Sweden, personal communication).

The clinical implication of this study is that, during exchange of ventilator filters, auto-triggering can maintain airway pressure above PEEP, but absence of auto-triggering may allow PEEP to be lost. The ventilator should therefore preferably be set to pressure controlled or supported mode, with a low triggering threshold. By doing so, the tracheal pressure is maintained. Furthermore, the suction support should not be activated.

\section{Limitations}

In the power analysis a priori, we estimated the number of subjects using a high power (0.95). In fact, a power analysis a posteriori showed 0.99 , indicating that it is not likely that filter exchange in the patient category studied leads to a deterioration in lung function. However, the clinical portion of the study was performed in subjects without extremely high PEEP levels or $\mathrm{F}_{\mathrm{IO}}$. With very high PEEP, even during pressure control, the flow and resistance in the ventilator tubing might not be adequate to maintain a sufficient airway pressure. In patients needing very high PEEP and/or $\mathrm{F}_{\mathrm{IO}_{2}}$, we still believe that ventilator filters should be exchanged with caution to avoid inadvertent lung collapse. Moreover, other brands of ventilators than the one used in this study may have other features, eg, the auto-triggering will be discontinued earlier, which needs to be considered. In particular, the finding in the bench test that only a short reduction of pressure occurred with vol- 
ume controlled ventilation is model- and brand-dependent. Furthermore, other tubing sets with other lengths and diameters could give other resistance patterns, which may influence the obtained airway pressure.

\section{Conclusions}

This prospective observational study in ICU subjects, mechanically ventilated in pressure modes with low triggering threshold settings, demonstrated that a short disconnection of the expiratory ventilator circuit from the ventilator during filter exchange was not associated with any significant deterioration in lung function. A bench test suggests that this result is explained by auto-triggering with high inspiratory flows during the filter exchange, maintaining the airway pressure.

\section{ACKNOWLEDGMENTS}

We express our gratitude to Ing-Marie Larsson, Ewa Wallin, and the ICU personnel at the University Hospital in Uppsala, Sweden for excellent help and dedication.

\section{REFERENCES}

1. Gattinoni L, D'Andrea L, Pelosi P, Vitale G, Pesenti A, Fumagalli R. Regional effects and mechanism of positive end-expiratory pressure in early adult respiratory distress syndrome. JAMA 1993;269(16): 2122-2127.
2. Briel M, Meade M, Mercat A, Brower RG, Talmor D, Walter SD, et al. Higher vs lower positive end-expiratory pressure in patients with acute lung injury and acute respiratory distress syndrome: systematic review and meta-analysis. JAMA 2010;303(9):865-873.

3. Neumann P, Berglund JE, Fernández Mondéjar E, Magnusson A, Hedenstierna G. Dynamics of lung collapse and recruitment during prolonged breathing in porcine lung injury. J Appl Physiol 1998; 85(4):1533-1543.

4. Dyhr T, Laursen N, Larsson A. Effects of lung recruitment maneuver and positive end-expiratory pressure on lung volume, respiratory mechanics and alveolar gas mixing in patients ventilated after cardiac surgery. Acta Anaesthesiol Scand 2002;46(6):717-725.

5. Dyhr T, Bonde J, Larsson A. Lung recruitment manoeuvres are effective in regaining lung volume and oxygenation after open endotracheal suctioning in acute respiratory distress syndrome. Crit Care 2003;7(1):55-62.

6. Lindgren S, Odenstedt H, Olegård C, Söndergaard S, Lundin S, Stenqvist O. Regional lung derecruitment after endotracheal suction during volume-or pressure-controlled ventilation: a study using electric impedance tomography. Intensive Care Med 2007;33(1):172180.

7. De Campo T, Civetta JM. The effect of short-term discontinuation of high-level PEEP in patients with acute respiratory failure. Crit Care Med 1979;7(2):47-49.

8. Maquet. Servo Duo Guard data sheet. http://www.maquet.com/content/documents / datasheet_optionaccessory/servo_data_duoguard_ rev01_en_all.pdf. Accessed August 15, 2013.

9. ARDS Definition Task Force, Ranieri VM, Rubenfeld GD, Thompson BT, Ferguson ND, Caldwell E, et al. Acute respiratory distress syndrome: the Berlin Definition. JAMA 2012;307(23):25262533. 